\title{
O gerenciamento de ferramentas de corte na indústria automotiva: um estudo de casos na região metropolitana de Curitiba
}

\author{
Alexandre Souto Favaretto \\ (TRITEC/PUCPR) \\ asf7@dcx.com \\ Pablo Deivid Valle \\ Pontifícia Universidade Católica do Paraná (PUCPR) \\ pablo.valle@pucpr.br \\ Osiris Canciglieri Junior \\ Programa de Pós-Graduação em Engenharia de Produção e Sistema da Pontifícia Universidade Católica \\ do Paraná (PPGEPS) \\ osiris.canciglieri@pucpr.br
}

\begin{abstract}
Atualmente, o cenário econômico mundial exige das empresas agilidade, flexibilidade no atendimento à demanda, foco intenso nos clientes, ciclos de vida de produtos abreviados, desenvolvimento constante de novas tecnologias e o desafio da redução de custos. Na indústria automotiva, em que a complexidade e o alto grau de desenvolvimento tecnológico de seus processos e produtos são significativos, verifica-se, sobremaneira, a necessidade crescente de eliminação de desperdícios e versatilidade, em geral. Parcelas significativas dos custos nesse segmento são representadas pelos processos de usinagem de componentes, sendo grande parte desses custos referente ao uso de ferramentas de corte. Nesse contexto, o gerenciamento eficiente de ferramentas de corte torna-se elemento importante para reduzir custos e eliminar desperdícios. O objetivo geral deste trabalho é identificar e debater, sob a óptica da produção enxuta, as principais práticas relacionadas ao gerenciamento de ferramentas de corte na indústria automotiva da cidade de $\mathrm{Cu}$ ritiba e Região Metropolitana, dando ênfase para o planejamento técnico. Observa-se assim que a gestão adequada e inteligente das ferramentas de corte proporciona ganhos relevantes em termos de tempo de manuseio e volume de itens em estoque.
\end{abstract}

Palavras-chave: ferramentas de corte, gerenciamento, administração da produção, desenvolvimento de produtos

The current economic global situation demands from companies more agility and flexibility to fulfill requests, intense focus on costumers, reduced product life cycle, constant development of new technologies and cost reduction. In the automotive industry, where complexity and high level of product and process technological development are significant it is verified the increasing demand for waste elimination and general serviceability. Significative parts of the costs are represented in this sector by the components manufacturing processes. In such context efficient cutting tool management became an important element to reduce cost and eliminate waste. The general aim of this work is to identify and discuss, under the lean manufacturing point of view, the main practices related to cutting tool management in the automotive industry in Curitiba and its metropolitan area, highlighting the technological planning. It can be observed that intelligent and adequate cutting tool management promotes relevant profits in handling time and volume of items in storage.

Keywords: cutting tools, management, production administration, product development

\section{Introdução}

O cenário mundial atual é marcado por incertezas tanto de ordem econômica quanto político-social. Há grande dificuldade em fazer previsões quanto ao crescimento dos mercados, ciclo de vida dos produtos, desenvolvimentos tecnológicos e novas formas de se fazer negócio. Este novo ambiente exige das empresas agilidade, flexibilidade no atendimento à demanda, foco intenso nos clientes, ciclos de vida de produtos abreviados, desenvolvimento 
constante de novas tecnologias e o desafio da redução de custos. É crescente o número de empresas que, em todo o mundo e em especial na indústria automotiva, têm buscado promover a melhoria contínua, eliminar desperdícios e reduzir custos através dos princípios da produção enxuta.

Dentro desse contexto, na indústria automotiva, devido à complexidade e ao alto grau de desenvolvimento tecnológico de seus processos e produtos, somam-se a necessidade crescente de diferenciação pelos baixos custos e flexibilidade. Uma parcela significativa dos custos nesse segmento são representados pelos processos de usinagem de componentes, e grande parcela desses custos são representados pelo uso de ferramentas de corte. Além do custo de aquisição, as ferramentas de corte impactam no custo final do produto por diversas maneiras, como: uso e manu-seio inadequado, gerando quebras e desperdícios; refugos no processo devido a ferramentas defeituosas; aplicação de capital para manutenção de estoques elevados; manutenção de grande número de ítens obsoletos em estoque devido a administração deficiente; elevados tempos de troca de ferramentas; e produção programada não realizada pela falta de ferramentas corretas no momento necessário. Esses são apenas alguns dos frequentes problemas que envolvem ferramentas de corte e que incidem diretamente no custo do produto acabado.

Assim, o gerenciamento de ferramentas de corte tem grande impacto na eficiência do sistema produtivo como um todo: afeta a disponibilidade de equipamentos, a qualidade do produto, a flexibilidade e o fluxo da produção, a disponibilidade de capital de giro - pela redução e controle dos estoques e os tempos de preparação de máquina, sendo importante fator de competitividade.

\section{0 gerenciamento de ferramentas de corte}

A diversidade e complexidade dos modernos sistemas de manufatura atuais indicam que o controle do ferramental não pode ser ignorado. Ao mesmo tempo em que buscase extrair o máximo das máquinas e ferramentas de corte, busca-se minimizar os custos diretos e indiretos relativos ao seu uso e minimizar o impacto que os problemas relativos à sua utilização têm no processo produtivo. Ao mesmo tempo que busca-se minimizar os estoques de ferramentas, e reduzir assim o custo financeiro do estoque e a obsolescência de materiais, busca-se também eliminar a falta de ferramentas.

A crescente demanda pela variedade de produtos, necessidade de menores lead time e produção em pequenos lotes — características da produção enxuta — exige que as ferramentas de corte estejam disponíveis no local e momento necessários à sua utilização, na qualidade adequada e ao menor custo possível. De acordo com Perera (1995), os seis principais problemas com ferramentas de corte são: alta variedade de ferramentas no processo, indisponibilidade de ferramentas, rastreamento e controle de ferramentas, alto inventário, falta de serviços de manutenção e custo do ferramental.

Perera (1995) também salienta que embora problemas como a falta de ferramentas afetem diretamente o desempenho do sistema produtivo como um todo, ainda há uma falta de entendimento sobre o papel do ferramental na manufatura. Vários autores têm escrito sobre a importância do gerenciamento de ferramentas em FMS (Sistemas Flexíveis de Manufatura), porém, a escala e natureza dos problemas com ferramentas na indústria tradicional, seu impacto na produtividade e como minimizá-los, ainda não foram suficientemente estudados. Ainda são poucos os autores que abordam o gerenciamento de ferramentas de forma sistêmica, envolvendo desde a compra até o descarte das ferramentas.

Assim sendo, torna-se clara a crescente importância do gerenciamento eficiente de ferramentas de corte, que surge como necessidade em empresas na rota da mentalidade enxuta, como forma de combate aos desperdícios que envolvem ferramentas de corte.

\subsection{Definição de gerenciamento de ferramentas de corte}

O gerenciamento eficaz de ferramentas é considerado hoje um importante diferencial competitivo. Para Masine (1998), o gerenciamento de ferramentas é definido como uma estratégia que visa à resolução dos problemas relacionados às varias atividades que envolvem o uso de ferramentas, incluindo aquisição, armazenagem, desenvolvimento de base de dados de ferramentas, seleção e alocação de ferramentas, inspeção, preparação (preset), entrega às linhas, troca, monitoramento e controle de inventário. $\mathrm{O}$ autor coloca ainda que o gerenciamento de ferramentas é uma abordagem organizada visando a garantir as ferramentas disponíveis para atingir os objetivos da produção, contribuindo para o aumento da produtividade e a eficiência. Boehs (1994) atesta que o gerenciamento de ferramentas é uma filosofia com abordagem disciplinada, na qual administram-se informações para tomada de decisão, fornecendo as ferramentas na quantidade necessária, no local desejado, no momento certo e na qualidade especificada.

Existem, na literatura e em prática no mercado, distintas abordagens no tocante a gerenciamento de ferramentas de corte. De acordo com Boogert (1994), a maioria dessas enfoca aspectos específicos do gerenciamento como: o gerenciamento de informações, a alocação de ferramentas, a reposição de ferramentas, e o controle do fluxo de ferramentas, sendo a grande maioria do material bibliográfico 
disponível voltado ao gerenciamento de ferramentas em FMS, no qual esse mostrou-se uma grande restrição quando não realizado de forma eficiente. Muitas abordagens consideram ainda a adoção de softwares ou a terceirização de serviços como definição de gerenciamento de ferramentas de corte. A adoção de softwares dedicados é certamente uma opção interessante, porém, algumas empresas têm investido em sistemas computadorizados para gerenciamento de ferramentas com o objetivo de resolver seus problemas com o ferramental. Contudo, sem um entendimento claro dos objetivos e funções do gerenciamento e sem uma estratégia definida, os benefícios destes sistemas tornam-se mínimos (PERERA, 1995). A abordagem do tema neste artigo é feita de modo sistêmico. Ao encontro da realidade da indústria automobilística atual, a análise é realizada sob a perspectiva da filosofia enxuta.

\subsection{Objetivos do gerenciamento de ferramentas}

Os propósitos primordiais do gerenciamento de ferramentas são aumentar a produtividade, eliminar os desperdícios e melhorar a qualidade dos produtos mediante a redução das interrupções no fluxo normal da produção. Tais interrupções ocorrem, por exemplo, quando há desgastes prematuros de ferramentas, quebras inesperadas, indisponibilidade, baixa qualidade nas peças, entre outros distúrbios que podem ocorrer nas linhas produtivas (GOLDONI, 2003).

Boogert (1994) coloca como objetivos macro do gerenciamento de ferramentas: a minimização dos distúrbios no processo de produção, a maximização da utilização dos recursos (máquinas e ferramentas), a redução do número de refugos e a redução dos custos gerais com ferramentas pela padronização e racionalização. Baseado nesses objetivos gerais, pode-se resumir como objetivos específicos do gerenciamento de ferramentas: reduzir estoques e obsolescência, padronizar as ferramentas utilizadas, eliminar a falta de ferramentas, aumentar a produtividade, reduzir o custo com ferramentas, controlar a localização e o fluxo de ferramentas no chão de fábrica, reduzir os tempos de preparação de máquinas, reduzir quebras de ferramentas, garantir a disponibilidade de informação precisa e atualizada, fortalecer relacionamento com fornecedores, garantir qualidade dos serviços de afiação e preparação de ferramentas, garantir a qualidade do produto produzido, garantir atualização tecnológica, e garantir o uso ecologicamente correto de ferramentas de corte.

O gerenciamento de ferramentas deve ser tratado como uma estratégia interdepartamental, tendo o apoio e comprometimento da alta gerência. Os objetivos só serão atingidos através do pleno entendimento, da cooperação e compartilhamento de objetivos e informações entre todos departamentos da empresa envolvidos como gerenciamento.

\subsection{Planejamento para o gerenciamento de ferramentas}

De acordo com Boogert (1994) e Boehs (2002 apud GOLDONI, 2003), para alcançar todos os benefícios propostos pelo gerenciamento de ferramentas, deve-se focar simultaneamente e de forma integrada o planejamento estratégico, logístico e técnico. O planejamento técnico lida com a seleção e com o uso de ferramentas; o planejamento logístico lida com a disponibilização das ferramentas no local e tempo certos, o planejamento estratégico envolve decisões que, por exemplo, podem limitar a variedade e quantidade de produtos que podem ser produzidos com o ferramental disponível. Nesta pesquisa, será explorado somente o planejamento técnico.

\subsubsection{Planejamento técnico}

A definição usual de planejamento técnico frisa a seleção e o uso de ferramentas de corte. Além do detalhamento de atividades relacionadas diretamente a esses aspectos, na abordagem aqui apresentada são acrescentadas atividades de responsabilidade do planejamento técnico que tem por foco atingir objetivos gerais e específicos do gerenciamento de ferramentas como, minimizar distúrbios no processo de produção devido a problemas com ferramentas, maximizar a utilização dos recursos (máquinas e ferramentas), minimizar o número de refugos, reduzir os custos gerais com ferramentas pela padronização e racionalização, controlar a localização e o fluxo de ferramentas no chão de fábrica, reduzir os tempos de preparação de máquinas, reduzir quebras de ferramentas, garantir a disponibilidade de informação precisa e atualizada, garantir qualidade dos serviços de afiação e preparação de ferramentas, e garantir a qualidade do produto produzido. Dentro do foco da produção enxuta, que busca o fluxo suave e contínuo da produção, foram acrescentadas também atividades como: controle da capabilidade de processo e vida de ferramentas, aplicação de Jidoka, gerenciamento visual, trabalho padronizado e kaizen. A definição de estratégia de inspeção de recebimento para ferramentas de corte também é responsabilidade do planejamento técnico. A Figura 1 ilustra essas atividades.

- Criação e manutenção de base de dados para ferramentas

O gerenciamento da informação é base do gerenciamento de ferramentas. A razão para isso é a grande quantidade de informação que é gerada e manipulada. Dados conflitantes, desatualizados ou simplesmente a falta de informação podem ser responsáveis por custos elevados, falta de ferramentas e inventário excessivo, entre vários 
outros problemas. A melhoria contínua também só é possível se houver uma base sólida, sabendo-se o estado atual e aonde se quer chegar. Boogert (1995) lembra que o ideal é a utilização de uma base de dados única, evitando informações em sistemas distintos, para evitar a possibilidade de dados redundantes e inconsistentes.

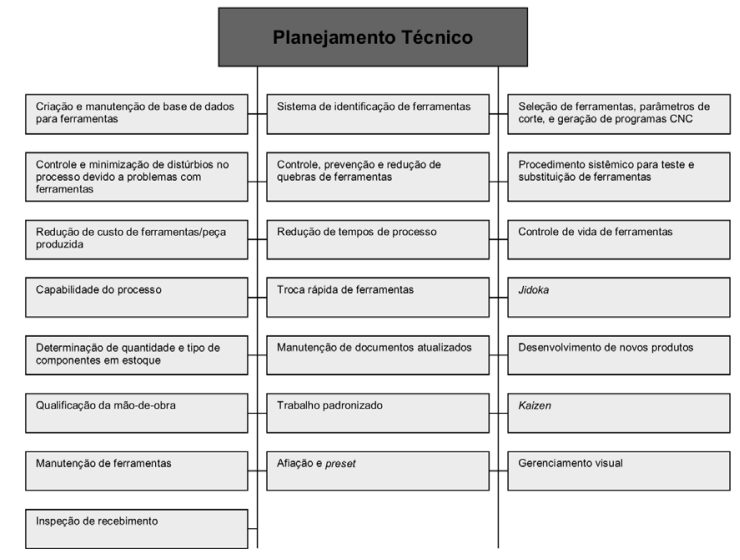

Figura 1 - Planejamento técnico

Quando da implementação do gerenciamento de ferramentas, a criação da base de dados e o cadastramento das ferramentas são as primeiras atividades a serem realizadas. Um cadastro padronizado e bem organizado facilita a localização, rastreabilidade, geração de controles, o processo de compras e levantamento de custos com ferramentas, evitando a existência de um mesmo item com cadastros diferentes.

Atualmente existem softwares dedicados que podem ser ajustados para atender as necessidades individuais de cada empresa. Independente do meio eletrônico que se use, o fundamental é ter em mente a relevância dos dados cadastrados e que tipo de informação se deseja obter, com vistas a atender as necessidades de todos os departamentos envolvidos com o gerenciamento de ferramentas. A base de dados deve prever também aspectos como o registro de anormalidades no processo, e é de grande importância que seja determinado um fluxo de informações de modo que a base esteja sempre atualizada.

\section{- Sistema de identificação de ferramentas}

A localização das ferramentas (montagens ou sets) na fábrica é apontada como um grande problema para várias empresas, como relata Perera (1995). Em seu fluxo pela fábrica, as ferramentas carregam consigo a informação do seu local de utilização. Ao pegar uma ferramenta, através de, por exemplo, uma gravação no porta-ferramenta, o operador deve ser capaz de identificar em que máquina, estação de trabalho ou fuso específico ela deve ser utilizada.

Os sets em giro de uma mesma ferramenta também devem ser diferenciados entre si, de forma que seja possível identificar problemas técnicos com uma ferramenta específica (xxx-1, $x x x-2, x x x-3$, etc.).
- Seleção de ferramentas, parâmetros de corte e geração de programas $\mathrm{CNC}$

A criteriosa seleção de ferramentas, parâmetros de corte e estratégias de usinagem para determinada operação são fatores determinantes para reduzir significativamente os possíveis distúrbios no processo, buscando atingir a especificação do produto e otimizando tempos e custos.

- Controle e minimização de distúrbios no processo devido a problemas com ferramentas

A produção enxuta busca o fluxo suave e contínuo dos produtos através das linhas de produção. Desta forma, minimizar os possíveis distúrbios, devido a problemas com ferramentas de corte, é um dos objetivos principais do gerenciamento de ferramentas.

Dentre os principais problemas com ferramentas que geram paradas não planejadas da produção estão a quebra, as colisões, a vida útil abaixo do especificado, as características do produto não conformes ao longo da vida da ferramenta e a primeira peça fora do especificado após a troca. A existência de padrões claros — da vida a ser cumprida (fixada em número de peças), dos procedimentos de limpeza, afiação, montagem, preset, troca na máquina e dos resultados dimensionais esperados na peça usinada, entre outros, - auxilia muito na redução dos problemas com ferramentas.

A informação é fator fundamental para resolver a maioria desses problemas, assim, é necessário que ela chegue aos responsáveis, ou seja, à engenharia de processo, à manutenção etc. É preciso conhecer onde estão concentrados os maiores problemas, com que frequência vêm ocorrendo e em que condições. Para isso ser possível é necessário um plano de reação a ser seguido pelos operadores quando ocorre uma anormalidade, acompanhado de uma sistemática de coleta de dados. O plano de reação evita que sejam feitas seguidas substituições de ferramentas sem que ações de solução ou contramedidas sejam tomadas. O plano deve indicar também o fluxo a ser seguido pela ferramenta com problema e que informações devem ser coletadas - preenchidas em, por exemplo, um cartão padrão para este tipo de ocorrências, que acompanhe a ferramenta até o setor de ferramentas. No setor de ferramentas, as informações devem ser compiladas na base de dados de forma a ajudar na priorização e na solução dos problemas e na avaliação de necessidade de adequação dos estoques.

- Controle, prevenção e redução de quebra de ferramentas

A prevenção de quebra é realizada principalmente pela seleção e aplicação adequada das ferramentas e pelo uso de máquinas-ferramentas em condições adequadas. 
No tocante à aplicação de Jidoka nos processos, atualmente existem diversos sistemas para assegurar a integridade das ferramentas, como monitoramento das forças de corte, do consumo de potência, controle de emissões acústicas ou vibrações. A utilização de "apalpadores" que checam a ferramenta ou a característica usinada — como profundidade de um furo - são também exemplos de poka-yokes frequentemente utilizados.

A coleta de informações é fundamental para encontrar os "focos" onde o problema se concentra e atacá-los de forma eficiente. Para a correta contabilização dos custos com quebra, é importante controlar o número de reafiações de cada ferramenta.

\section{- Redução de custo/peça}

Parcela significativa do tempo disponível da engenharia de processos deveria ser gasta com atividades de redução de custos. Como já citado, para que o retorno desse tempo e esforço despendido seja maximizado, é necessário que se atue sobre os ítens de maior gasto por peça produzida. A base de dados deve ser capaz de fornecer o custo/ peça por ordem decrescente.

Na contabilização do custo por peça produzida, deve-se levar em conta ao menos os seguintes fatores: custo direto por peça (preço da ferramenta/número total de peças produzidas), custo de troca de ferramentas (tempo de troca de ferramentas $\mathrm{x}$ custo hora máquina), custo de preparação, e custo de afiação. Vários outros fatores podem entrar na composição do custo por peça, como o custo com mão de obra.

\section{- Redução de tempos de processo}

A atividade de redução de tempos de processo — para "quebrar" gargalos, permitir a fabricação em pequenos lotes e reduzir lead-time — está diretamente vinculada às ferramentas de corte. A otimização dos tempos passa pela redução dos tempos improdutivos (movimentos em que a ferramenta não está efetivamente em corte durante o ciclo), dos tempos de corte e dos tempos de troca de ferramenta.

A constante atualização tecnológica de máquinas e ferramentas de corte permite velocidades de corte e avanços cada vez maiores, porém, com custos muitas vezes elevados. Saber em que etapas do processo aplicar essas tecnologias de forma a aumentar a capacidade geral das linhas (foco nos gargalos) é o grande desafio para manter custo sob controle.

- Procedimento sistêmico para teste e substituição de ferramentas
A realização de testes de ferramentas com novos materiais, geometrias, coberturas, parâmetros de corte e estratégias de usinagem é o que garante a contínua redução de custos. Porém, para que a redução seja realmente efetiva, é necessário que haja uma estratégia definida, focando, como já dito, nos principais custos.

Algumas falhas no processo que fazem com que a redução de custos seja menor do que poderia ser são, por exemplo, falta de estratégia de priorização das ferramentas a serem testadas; avaliação somente do fator preço; desconsideração da quantidade em estoque do item a ser substituído gerando custos com obsolescência; falta de avaliação do tempo de retorno para investimentos em novos porta-ferramentas e componentes; não atualização de documentos dos processos (planos e desenhos de ferramentas); avaliação deficiente da quantidade a ser colocada em estoque, gerando paradas de produção ou estoques excessivos; não avaliação da capacidade do processo com a nova alternativa; desconsideração de custos indiretos, como tempos de preparação e troca de ferramentas; desconsideração do histórico de relacionamento com o fornecedor; e desconsideração de ferramentas em processo de fabricação nos fornecedores, gerando prejuízos aos mesmos e enfraquecimento da relação.

A postura inadequada frente aos fornecedores de ferramentas é um problema frequente que ocorre no teste e na substituição de ferramentas. É importante que seja levado em consideração o fortalecimento da parceria com fornecedores, estimulando a cooperação mútua. $\mathrm{O}$ fornecedor deve buscar trabalhar junto com a empresa na busca pela redução de custos, porém, para tanto, é necessário que informações sejam compartilhadas e que ele conheça as prioridades, de forma a estar sempre buscando alternativas. Para que o fornecedor possa investir, buscando um relacionamento de longo prazo, é necessário que sinta seu trabalho valorizado e tenha garantias que terá as mesmas oportunidades que seus concorrentes em casos de substituição.

Para que os processos de teste e aprovação de um novo item até sua entrada em giro não provoquem distúrbios, é necessário que o procedimento de testes seja de conhecimento e uso de todos setores envolvidos (operações, engenharia de processo, logística e compras), que esses trabalhem em conjunto e que se estabeleça um fluxo em que a informação chegue aos interessados na seqüência e no tempo adequados.

\section{- Capacidade do processo}

Para evitar a ocorrência de refugos e retrabalhos, é importante conhecer a influência das ferramentas no comportamento do processo e as alterações que ocorrem na capacidade devido a desgastes e/ou trocas de ferramenta. 
Os desgastes de ferramenta provocam alterações de requisitos dimensionais e superficiais das peças usinadas. $\mathrm{O}$ aumento dos esforços de corte devido ao desgaste também pode provocar alterações se a rigidez do conjunto máquina-ferramenta não for adequada às forças exercidas. Estudos de capacidade devem ser utilizados para auxiliar na determinação da vida útil de ferramentas. Além disso, tolerâncias construtivas das ferramentas também podem afetar a capacidade dos processos ao se efetuar a troca de ferramentas.

\section{- Controle de vida de ferramentas}

Alguns dados relevantes que podem ser coletados em cada troca de ferramentas são, por exemplo, vida atingida, condição do produto (conforme) na primeira peça usinada, condição do produto (conforme) na última peça usinada, operador que realizou a troca, horário em que a troca foi feita, tempo utilizado e detalhes de possíveis anormalidades do produto ou ferramenta. Meios eletrônicos, através dos computadores das máquinas-ferramenta, já são utilizados para registrar essas informações, que são em seguida compiladas em um banco de dados, evitando o trabalho de passar as informações do formulário de papel para a base de dados.

Distúrbios como vida útil não cumprida ou quebras devem ser encaminhados de forma especial e padronizada para o setor de ferramentas.

Mudanças nas vidas das ferramentas, para mais ou para menos, alteram o consumo mensal. Para que não ocorram situações de falta ou excesso de estoque deve haver um fluxo para que essas flutuações de vida útil, uma vez detectadas, acionem ações de adequação de volumes em estoque.

- Determinação de quantidade e tipo de componentes em estoque

A falta de um critério para colocação de componentes em estoque pode levar a se ter componentes estocados que raramente serão utilizados ou componentes que, caso sejam necessários, demorem semanas para ser entregues, provocando parada de linha. A possibilidade de desgaste e dano, facilidade de aquisição e fabricação e o prazo de entrega devem ser fatores determinantes para a escolha de ítens a serem colocados em estoque e de suas respectivas quantidades.

\section{- Troca rápida de ferramentas (TRF)}

A essência da TRF é a redução dos tempos de preparação de máquina (setup). O planejamento técnico deve levar em consideração a aplicação das técnicas TRF quando da aplicação de ferramentas de corte.
- Jidoka

A aplicação do Jidoka no gerenciamento de ferramentas se dá principalmente através de dispositivos poka-yoke utilizados nas ferramentas e nas máquinas, indicando a ocorrência de anormalidades e parando o processo quando de sua ocorrência. Controles de potência que alarmam quando uma ferramenta está cortando sobremetal em excesso, poka-yokes que indicam quebra de ferramentas e pokayokes que evitam que ferramentas sejam montadas na posição ou local errados são alguns exemplos de aplicação de Jidoka nos processos de usinagem.

- Manutenção de documentos atualizados

A manutenção dos documentos como os planos e desenhos de ferramentas são fundamentais para evitar diversos problemas e longas paradas de máquina. Todas as alterações no processo devem ser atualizadas na documentação o mais breve possível, de modo que todos os envolvidos possam tomar as ações que lhes cabem, caso seja necessário.

\section{- Desenvolvimento de novos produtos}

É na fase de desenvolvimento que devem ser levantadas e minimizadas as possíveis dificuldades do processo para a fabricação do produto. Possibilidades de padronização de características para utilização de ferramentas já existentes e de modificações para facilitar a fabricação, que não afetem a funcionalidade do produto, devem ser perseguidas.

- Qualificação da mão de obra

Na produção enxuta, a necessidade é de mão de obra qualificada e multifuncional, capaz de tomar decisões em seu ambiente de trabalho. Standart e Davis (1999 apud TURINO, 2002) afirmam que um profissional que trabalha de acordo com os princípios da produção enxuta pode contribuir de maneira mais efetiva na redução de custos e na eliminação de estoques desnecessários de ferramentas de corte.

A qualificação dos técnicos que trabalham com ferramentas, bem como dos usuários, traz grandes benefícios em praticamente todas atividades realizadas dentro do gerenciamento de ferramentas. Deve-se buscar que os envolvidos com preparação, afiação e uso de ferramentas sejam capazes de manuseá-las de forma adequada, avaliar condições de desgaste, avaliar quebras, melhorar afiações, entre outras atividades, mas principalmente colaborar de maneira efetiva na resolução de problemas e melhoria contínua, utilizando uma metodologia científica. Todos os envolvidos devem ser treinados na filosofia e nas técnicas da produção enxuta. 
- Trabalho padronizado

Envolve seguir padrões de maneira consistente, de modo que qualquer problema na sequência do trabalho realizado apareça repetidamente. Assim é possível identificar os problemas com facilidade e corrigí-los prontamente. $\mathrm{O}$ trabalho padronizado permite fixar as melhorias obtidas e mostrar as novas oportunidades de ganho.

Toda atividade no gerenciamento, desde a afiação da ferramenta até a montagem na máquina, deve ser especificada em seu conteúdo, sequência, tempo e resultado esperado. As instruções de trabalho devem ser feitas pelos próprios técnicos e operadores, com o apoio das lideranças. O uso de padrões visuais pode auxiliar a execução dos trabalhos de maneira padronizada.

\section{- Kaizen}

O kaizen é a ferramenta que traz a melhoria contínua para a prática. Problemas como estoque em excesso de determinada ferramenta, atraso na entrega de ferramentas para as linhas, erros de preset, fluxo inadequado dentro do setor de ferramentas e tempo excessivo de preparação, são exemplos de temas para kaizen no gerenciamento. Como na produção enxuta, é importante que no gerenciamento de ferramentas incentive-se os envolvidos a continuamente repensar os processos, utilizando-se metodologia científica para resolução dos problemas.

\section{- Manutenção de ferramentas}

Se não mantidos de forma adequada e inspecionados com frequência definida, danos e problemas dimensionais, provenientes de colisão ou desgaste em porta-ferramentas (corpos de fresa, adaptadores, barras de mandrilar, portamachos etc.), podem afetar negativamente a vida de ferramentas de corte e provocar quebras. É importante manter uma rotina de inspeção e substituição de componentes, definindo tipos e quantidades que necessitam ser mantidos em estoque.

Como no caso de fornecedores de ferramentas de corte, deve-se buscar estabelecer uma efetiva parceria com fornecedores de porta-ferramentas e componentes.

\section{- Afiação e ajustagem}

As atividades de afiação e ajustagem (preset) de ferramentas são elementos básicos pertinentes ao uso de ferramentas de corte. Nessas atividades trabalha-se geralmente com grande necessidade de precisão, e qualquer problema é refletido como refugo e parada de produção no momento da utilização das ferramentas.
É fundamental o treinamento, a utilização de equipamentos adequados e a utilização de instruções detalhadas de trabalho que pormenorizem conteúdo, sequência, tempo, equipamentos a serem utilizados e resultado esperado. É importante que os desenhos e planos de ferramentas sejam suficientemente detalhados para fornecer todas as informações necessárias à execução dessas atividades.

É importante que o ambiente físico seja adequado para poder-se atingir o grau de precisão requerido das atividades de preset.

\section{- Inspeção de recebimento}

Problemas dimensionais com ferramentas de corte, mais usuais com ferramentas rotativas inteiriças (brocas, machos, fresas etc.), devido à natureza de seus processos de fabricação, podem causar grandes perdas — incluindo parada de produção - se não detectados a tempo.

Deve-se buscar desenvolver os fornecedores de modo a atingir a qualidade assegurada, eliminando-se a inspeção de recebimento. Esse trabalho deve ser elaborado de modo a avaliar sistematicamente o desempenho dos fornecedores, reduzindo ou aumentando a amostragem e frequência de inspeção de recebimento de acordo com os resultados obtidos. Esses, somados a outros fatores como pontualidade da entrega e assistência técnica, devem fazer parte da avaliação geral do fornecedor, servindo como critérios para fortalecimento ou desistência da parceria.

\section{Metodologia de pesquisa}

O objetivo desta pesquisa exploratória foi identificar, sob a óptica da produção enxuta, as principais práticas relacionadas ao gerenciamento de ferramentas de corte na indústria automobilística da cidade de Curitiba e Região Metropolitana. Neste artigo são apresentados resultados referentes ao planejamento técnico.

Visando a qualidade da pesquisa, buscou-se o estudo de casos múltiplos, através de entrevistas estruturadas. O critério para escolha das empresas estudadas foi o volume de consumo de ferramentas de corte, levando-se em consideração a acessibilidade a essas. A amostra foi escolhida com base em pesquisa realizada com cinco grandes fornecedores de ferramentas de corte. A partir desses resultados foram escolhidas dez empresas. A escolha baseouse no critério referente ao número de vezes em que as empresas apareceram nas respostas dos entrevistados. Na amostra existem montadoras, fabricantes de motores, e fornecedores de componentes usinados. Todas entrevistas foram realizadas dentro das próprias empresas, de forma que na maioria dos casos foi possível visualizar o ambiente descrito pelos entrevistados. O tempo total de gravação das dez entrevistas foi de aproximadamente vinte e uma horas. 


\section{Análise e discussão de resultados}

A Tabela 1 caracteriza a amostra. $\mathrm{O}$ gasto anual com ferramentas de corte dentro da amostra varia de $\mathrm{R} \$ 300.000,00$ a $\mathrm{R} \$ 40.000 .000,00$.

\subsection{Principais problemas com ferramentas de corte}

Foi solicitado aos entrevistados que listassem, por ordem de importância, seus 5 maiores problemas com ferramentas de corte. O resultado é apresentado na Tabela 2. Os resultados foram obtidos após multiplicar-se as classificações do problema por um fator de peso, atribuído como 5 para o principal problema, 4 para o segundo, 3 para o terceiro maior, e assim por diante. Figuram como os três principais problemas apontados o custo, a qualidade das ferramentas e os prazos de entrega.

Tabela 1- Caracterização geral

\begin{tabular}{|c|c|c|c|c|c|c|c|c|c|c|}
\hline & \multicolumn{10}{|c|}{ Empresa } \\
\hline & $\mathbf{A}$ & B & $\mathbf{C}$ & $\mathbf{D}$ & $\mathbf{E}$ & $\mathbf{F}$ & G & $\mathbf{H}$ & $\mathbf{I}$ & $\mathbf{J}$ \\
\hline Área construída $\left(\mathrm{m}^{2}\right)$ & 40000 & 5000 & 12000 & 10000 & 75000 & 40000 & 2850 & 2000 & 10000 & 40000 \\
\hline Produtos em linha & 4 & 11 & 2 & 10 & 5 & 23 & 800 & 8000 & 20 & 12 \\
\hline $\begin{array}{l}\text { Componentes usinados } \\
\text { internamente }\end{array}$ & 4 & 4 & 4 & 10 & 700 & 23 & 800 & 8000 & 20 & 3 \\
\hline$\%$ produção mercado interno & $0 \%$ & $70 \%$ & $30 \%$ & $75 \%$ & $40 \%$ & $50 \%$ & $100 \%$ & $70 \%$ & $40 \%$ & $50 \%$ \\
\hline$\%$ produção mercado externo & $100 \%$ & $30 \%$ & $70 \%$ & $25 \%$ & $60 \%$ & $50 \%$ & $0 \%$ & $30 \%$ & $60 \%$ & $50 \%$ \\
\hline $\begin{array}{l}\text { Volume produzido 2004- } \\
\text { componentes (milhares) }\end{array}$ & 200 & 4500 & 17 & 7500 & 12000 & 250 & 4176 & 1200 & 40 & 600 \\
\hline Tipo produção & Série & Série & Série & Série & Série & Série & Lotes & Lotes & Série & Série \\
\hline Característica do maquinário & rígido & flexível & rígido & flexível & flexível & flexível & flexível & flexível & rígido & flexível \\
\hline Capital & Multinac. & Multinac. & Multinac. & Nacional & Multinac. & Multinac. & Nacional & Nacional & Nacional & Multinac. \\
\hline
\end{tabular}

Tabela 2 - principais problemas com ferramentas de corte

\begin{tabular}{|c|c|c|c|c|c|c|}
\hline & $1^{\circ}$ & $2^{\circ}$ & $3^{\circ}$ & $4^{\circ}$ & $5^{\circ}$ & Total \\
\hline Custo & $40 \%$ & $10 \%$ & & & & 240 \\
\hline Qualidade da ferramenta & $20 \%$ & & $10 \%$ & $10 \%$ & & 150 \\
\hline Prazo de entrega & & $30 \%$ & $10 \%$ & & & 150 \\
\hline Manuseio inadequado (pela produção) & $10 \%$ & & $10 \%$ & & & 80 \\
\hline Falta de conhecimento de aplicação & & $10 \%$ & $10 \%$ & & $10 \%$ & 80 \\
\hline Erros de preset & & $10 \%$ & & $10 \%$ & & 60 \\
\hline Falta de ferramentas na linha & $10 \%$ & & & & $10 \%$ & 60 \\
\hline Quebra & $10 \%$ & & & & & 50 \\
\hline Falta de controle da vida útil & $10 \%$ & & & & & 50 \\
\hline Condição das máquinas-manutenção & & $10 \%$ & & & & 40 \\
\hline Falta de tempo para otimização & & $10 \%$ & & & & 40 \\
\hline Falta de controle da vida de componentes & & $10 \%$ & & & & 40 \\
\hline Atraso de entrega dos fornecedores & & $10 \%$ & & & & 40 \\
\hline Falta de padronização (procedimentos) & & & $10 \%$ & & & 30 \\
\hline Erros de reafiação & & & $10 \%$ & & & 30 \\
\hline Falta de controle de estoque & & & $10 \%$ & & & 30 \\
\hline Mudança na programação do cliente & & & $10 \%$ & & & 30 \\
\hline Atendimento de fornecedores & & & $10 \%$ & & & 30 \\
\hline Dados de corte inadequados & & & $10 \%$ & & & 30 \\
\hline Oscilação de características da matéria-prima & & & & $10 \%$ & $10 \%$ & 30 \\
\hline Oscilação de desempenho & & & & $10 \%$ & & 20 \\
\hline Oscilação de consumo & & & & $10 \%$ & & 20 \\
\hline Subutilização & & & & $10 \%$ & & 20 \\
\hline Documentação técnica deficiente & & & & $10 \%$ & & 20 \\
\hline Estoque elevado & & & & & $10 \%$ & 10 \\
\hline Baixa vida útil & & & & & $10 \%$ & 10 \\
\hline
\end{tabular}


O resultado das questões feitas aos entrevistados visando a compreender as práticas vinculadas ao planejamento técnico no gerenciamento de ferramentas, são apresentadas a seguir.

\subsection{Cadastro e base de dados de ferramentas}

Pôde-se observar que $90 \%$ dos entrevistados indicaram o cadastro em base de dados corporativa, cujo objetivo principal é o gerenciamento da parte logística e de compras. Apenas 30\% indicaram haver base de dados específica para ferramentas de corte e, apesar do crescente interesse no assunto, apenas $10 \%$ dos entrevistados fazem uso de software de gerenciamento de ferramentas.

Foi solicitado aos entrevistados que indicassem quais informações são atualmente cadastradas na base de dados, referentes a ferramentas de corte, como ilustrado na Figura1.

Os baixos percentuais obtidos para informações importantes cadastradas na base de dados (Figura 2) - como vida útil média (40\%), número de arestas de corte (40\%), número de reafiações (30\%), e dados de corte - são coerentes com o baixo percentual de empresas que indicaram possuir base de dados específica ou software para gerenciamento de ferramentas (40\%). É importante ressaltar que informações como vida útil e número de reafiações de ferramentas são fundamentais para o controle de custos e para a priorização de ações de redução de custo (indicado como principal problema na Tabela 3). Sessenta porcento $(60 \%)$ dos entrevistados afirmaram que os dados que utilizam são confiáveis.

Figura 2 - Ítens cadastrados na base de dados

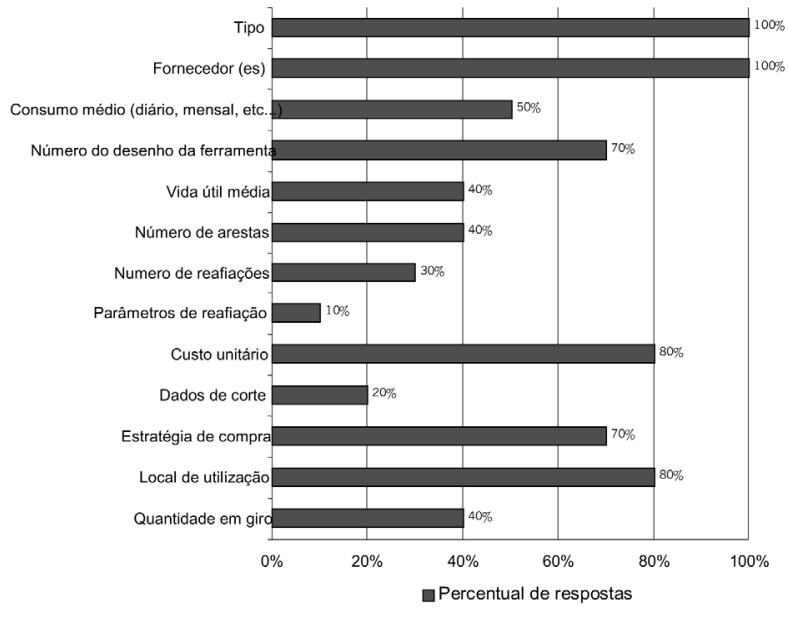

\subsection{Identificação e rastreabilidade das ferramentas}

Em uma das empresas, todas ferramentas, duráveis ou perecíveis, são identificadas com um código. As ferra- mentas perecíveis (brocas, alargadores, fresas etc) já são recebidas dos fornecedores com uma gravação na haste, onde está gravado o código da ferramenta (que identifica o produto e a máquina onde é utilizada) e o número de cadastro no estoque. As ferramentas duráveis (corpos de fresa, adaptadores, barras de mandrilar etc) têm gravado no seu corpo um código que identifica o produto e a máquina em que são utilizadas. O entrevistado salienta que a informação, em sua visão, deve ser carregada pela própria ferramenta, e complementa que na empresa não é utilizado nenhum tipo de controle em papel para rastreabilidade de ferramentas. $\mathrm{O}$ padrão definido da quantidade de ferramentas em giro - uma em uso, uma na espera da máquina, e outra no supermercado - garante a localização das ferramentas.

Em outra empresa, as ferramentas recebem marcação (código) quando saem do estoque, identificando seu local de utilização e um número sequencial que individualiza a ferramenta. O objetivo, segundo o entrevistado, é possibilitar controles como o número de reafiações.

Outra forma de rastreabilidade apontada foi o uso de contenedores com a codificação das ferramentas — etiquetas ou fichas. Em uma das empresas, a cada ciclo, a ferramenta recebe uma nova ficha, que, após cumprida a vida da ferramenta, é arquivada em uma pasta da operação. Nesta ficha, são anotados os dados de vida útil, o preparador, o operador e os detalhes do desempenho da ferramenta.

\subsection{Seleção de ferramentas para o processo}

Com relação à seleção de ferramentas para o processo, pôde-se observar pelas respostas que, apesar da diferença em alguns pontos, o foco principal da maioria dos entrevistados está ligado às questões de custo, qualidade e prazo de entrega (em consonância com a Tabela 3), delegando os aspectos técnicos da seleção de ferramentas aos fornecedores, selecionados por diversos critérios. Esse padrão vai ao encontro do que Goldoni (2002) coloca como uma das característica do fornecimento nos moldes evoluídos: a participação efetiva dos fornecedores no planejamento técnico dos clientes.

Em seguida, foi questionado como as ferramentas de corte eram consideradas durante o desenvolvimento de novos produtos. Pôde-se observar que atualmente as ferramentas de corte são pouco consideradas ou estão começando a ser consideradas durante o desenvolvimento de novos produtos. Apesar de divergências quanto ao assunto, aparecem claros, na visão da maioria dos entrevistados, a importância de o fator ferramentas de corte ser considerado durante o desenvolvimento de novos produtos e os primeiros passos que já estão sendo dados nesta direção. 


\subsection{Capacidade dos processos}

Cinquenta porcento $(50 \%)$ dos entrevistados responderam não considerar ferramentas de corte na avaliação da capabilidade dos processos, tampouco durante a aprovação de novas ferramentas, apesar de reconhecerem a importância das mesmas.

\subsection{Documentação técnica}

Quanto à documentação técnica, 60\% dos entrevistados entendem que sim, são mantidas atualizadas. Noventa porcento $(90 \%)$ concordam que a documentação contém as informações necessárias para os trabalhos realizados pela central de ferramentas.

\subsection{Trabalho padronizado}

Quando perguntado sobre a importância da padronização das atividades e processos para a empresa, os entrevistados citaram que esta é importante para: manter constante a qualidade dos produtos e processos; manter o foco; possi-bilitar melhoria continua e resolução rápida de problemas; treinamento e distribuição de conhecimento; organização da fábrica; redução de custo; economia de tempo e bom seguimento das ações. Os entrevistados afirmam que existem instruções de trabalho para a maioria das atividades realizadas nas centrais de ferramentas, porém reconhecem oportunidades de melhoria quanto ao conteúdo e quanto ao uso efetivo das mesmas.

\subsection{Preset e afiação de ferramentas}

Na maioria das empresas, o preset de ferramentas é feito exclusivamente pelo pessoal das centrais de ferramentas. Três entrevistados indicaram que algumas atividades de preset também são realizadas pelos operadores. Em uma das empresas, toda montagem e preset de brocas, machos e alargadores são feitos dentro das próprias linhas de produção pelos operadores, ficando a cargo da central de ferramentas as fresas e as barras de mandrilar. Para esse entrevistado, é vantagem ter os operadores com a responsabilidade do preset, pois, assim, eles passam a conhecer melhor o ferramental e a ser responsáveis por todo processo.

Em outra empresa, cada operador tornou-se responsável por "pressetar" as ferramentas das máquinas nas quais trabalha. Para o entrevistado, esse método trouxe uma importante economia de mão de obra, aproveitando o tempo ocioso decorrente de um processo altamente automatizado e possibilitando aperfeiçoamento da mão de obra. $\mathrm{O}$ entrevistado indica que houve aspectos negativos no início, devido ao fato de que, com várias pessoas lidando com várias ferramentas, em três turnos de trabalho, há perda de controle e padronização. Porém, acredita que em cerca de um ano, com todo pessoal bem treinado e com mais conhecimento sobre as ferramentas, o processo estará estável novamente.

Noventa porcento (90\%) dos entrevistados acreditam que os técnicos de preset não devem ser dedicados a grupos específicos de ferramentas ou tecnologias, mas sim serem polivalentes e capazes de trabalhar com todas ferramentas que a empresa utiliza. Acreditam que com a polivalência ganha-se em flexibilidade, conhecimento e satisfação pessoal. Sessenta por cento $(60 \%)$ dos entrevistados indicaram, porém, que ao lado da polivalência, é necessário que os técnicos tenham conhecimentos específicos. Um dos entrevistados comentou que “(...) se você souber combinar o elevado conhecimento específico e a multifuncionalidade, você tem uma equipe realmente forte". Outro entrevistado comentou que entende por multifuncional o técnico que "(...) entenda de afiação, de regulagem e de montagem da ferramenta na máquina, que saiba analisar e resolver problemas, e que seja capaz de promover melhoria contínua e otimização dos processos". Em duas das empresas, é feito rodízio de pessoal na central de ferramentas, inclusive com o pessoal da afiação, para multiplicar o conhecimento dentro da área.

Três entrevistados indicaram que há controle sobre os tempos e as ferramentas que são preparadas. Para um desses entrevistados, esse controle serve para avaliar se o trabalho está sendo realizado de acordo com o padrão estabelecido nas instruções de trabalho, para que possam ser feitos ajustes, melhorias e, se necessário, treinamentos, e para que possa ser medida a eficiência individual de seus funcionários. Outro entrevistado comentou que o controle dos tempos de preparação serve para priorizar as ferramentas a serem preparadas.

Em 30\% das empresas a afiação é 100\% terceirizada; em $10 \%$ a afiação é feita $100 \%$ internamente; e nas demais a maioria das ferramentas é afiada internamente, sendo que algumas são enviadas para afiação em terceiros, devido a restrições de capacidade ou tecnologia.

Pôde-se observar que $40 \%$ dos entrevistados consideram a afiação de ferramentas um problema na empresa, e apontam dificuldades com a falta de conhecimento de geometria de ferramentas, a falta de conhecimento de parâmetros de retificação (como tipo e granulometria do rebolo) e a falta de informação nos desenhos de afiação (documentação técnica deficiente). Dos $70 \%$ que reafiam ferramentas internamente na empresa, apenas $43 \%$ concordam que o processo é padronizado.

Apenas 30\% dos entrevistados não controlam o número de afiações das ferramentas. Dos $70 \%$ que controlam, alguns utilizam uma ficha para cada tipo de ferramenta, nas quais são marcadas as reafiações feitas, outros utilizam apenas marcações ("risquinhos") na haste das ferramentas e outros, ainda, utilizam marcação nas hastes junto com 
as fichas. O objetivo comum é o controle mais detalhado de custo/peça, dos custos com quebras e, por possibilitar saber o quanto a ferramenta está próxima de sua última afiação, facilitando a programação de compras.

Quanto à quantidade de material removido em cada afiação, 80\% dos entrevistados colocam que é determinada pela experiência do afiador e pela análise do desgaste da ferramenta. Dois entrevistados colocaram pontos de vista interessantes quanto à padronização da quantidade de material a ser removido, em prol da maximização do uso das ferramentas. O primeiro comentou que determina a vida da ferramenta com base na quantidade de material que pretende remover na afiação, balanceando, assim, a vida útil da ferramenta e o número de reafiações possíveis, considerando também os tempos de troca de ferramenta na máquina. O segundo entrevistado comentou que os afiadores avaliam o desgaste das ferramentas em seus primeiros ciclos de vida e, ao constatarem o pior caso - maior quantidade de material a ser removido padronizam o valor para aquelas ferramentas, dentro do programa de afiação.

Apenas $10 \%$ dos entrevistados consideraram o preset de ferramentas um problema na empresa e que $60 \%$ consideram-no adequadamente padronizado.

\subsection{Estrutura e ambiente das centrais de ferramentas}

Cem porcento (100\%) dos entrevistados declararam que consideram o ambiente adequado nas centrais de ferramentas de suas empresas, levando em conta aspectos como limpeza, luminosidade e temperatura.

\section{10 Inspeção de recebimento}

Pôde-se observar nos relatos que, das dez empresas entrevistadas, apenas quatro (40\%) possuem sistemática de inspeção de recebimento. Cruzando as respostas com os dados de gasto anual com ferramentas (Tabela 1), pôdese observar que as quatro empresas que apresentam maior preocupação com a inspeção de recebimento estão entre as cinco com maior gasto anual com ferramentas. Apenas uma empresa entre as cinco com maior gasto não possui uma sistemática definida de inspeção. É importante ressaltar que a qualidade das ferramentas recebidas foi apontada como segundo maior problema relativo a ferramentas de corte pelos entrevistados (Tabela 3).

Observou-se também que das cinco maiores empresas com maior gasto anual com ferramentas (Gráfico 1), apenas uma trabalha com qualidade assegurada, sem nenhuma inspeção. Em dois depoimentos, também entre as cinco de maior consumo, fica claro que a lógica free-pass, característica da qualidade assegurada, não vem sendo utilizada para ferramentas rotativas, nas quais a incidência de problemas aparenta ser maior. Para insertos, notase nas respostas maior confiança na qualidade do recebimento.

Um dos entrevistados sugere em sua resposta que, sem inspeção de recebimento, pode não haver comprometimento com a qualidade por parte de alguns fornecedores, pela certeza de não reprovação do lote em um primeiro momento. Outro entrevistado salienta que a baixa qualidade o obriga a manter maiores estoques de ferramentas.

\subsection{Manutenção de ferramentas}

Ao questionar-se sobre como era determinada a vida útil de corpo de fresa, porta-ferramentas, barras e componentes, $80 \%$ dos entrevistados declararam não existir vida útil pré-determinada, sendo o controle realizado visualmente pela verificação da presença de marcas, batidas ou desgastes. A troca é realizada quando um defeito é encontrado, em processo reativo. Desses $80 \%, 50 \%$ declararam que consideram esse controle importante de ser realizado. Dez porcento (10\%) estão em fase de implementação da determinação de vida de componentes, e apenas $10 \%$ já realizam manutenção de ferramentas preventivamente, incluindo revisão de corpos de fresa.

Um dos entrevistados mantém contrato com uma empresa — selecionada após concorrência e avaliação — apenas para pequenos serviços de recuperação de porta-ferramentas, pagos por hora trabalhada. $\mathrm{O}$ entrevistado declara que esse contrato permitiu maior agilidade na recuperação.

\section{12 Redução de tempos de ciclo de processo}

Foi solicitado aos entrevistados que classificassem, de acordo com a prioridade que dão ao realizar testes de ferramentas, os objetivos de: redução de tempo de ciclo, aumento de vida útil, redução de tempos de preparação, redução de custo, redução de quebras de ferramentas e melhorias de qualidade. Trinta porcento $(30 \%)$ consideram prioridade atividades de redução de tempo de ciclo, $20 \%$ consideram prioridade 2 e $30 \%$ consideram prioridade 3 , figurando essa, devido às características de produção e demanda das empresas, como uma importante atividade.

\subsection{Troca rápida de ferramentas}

Sessenta porcento $(60 \%)$ dos entrevistados concordam que seus funcionários trabalham com melhorias de setup, e apenas $40 \%$ concordam que seus funcionários são treinados para redução dos tempos de setup. O conjunto das respostas indica que a TRF, no conceito utilizado pela Toyota, não é amplamente utilizada, sendo a busca pela redução dos tempos de máquina parada para troca de 
ferramentas feita através do aumento de vida de ferramentas.

\subsection{Qualificação da mão de obra}

No tocante à mão de obra, a primeira questão realizada foi sobre a qualificação dos profissionais nas centrais de ferramentas. Pelas respostas, observa-se que em geral os entrevistados consideram que os técnicos das centrais de ferramentas devem ser ativos e capazes de: avaliar desgastes e condições anormais nas ferramentas; avaliar se a vida útil está adequada ou se deve ser aumentada ou reduzida de acordo com o desgaste; definir quanto material deve ser removido na afiação, bem como sugerir o balanço entre vida da ferramenta e material a ser removido, para obter a melhor relação de custo. Alguns depoimentos indicam a necessidade de aperfeiçoamento da mão de obra e a dificuldade de encontrar no mercado profissionais já treinados nessa área. Nesse cenário, as empresas devem buscar minimizar a alta rotatividade de funcionários através de boas condições gerais de trabalho, e estabelecer claramente o perfil desejado dos funcionários, preparando, em seguida, planos de capacitação.

Setenta porcento $(70 \%)$ dos entrevistados indicaram que existe matriz de treinamento específica para a central de ferramentas, em que os aspectos técnicos figuram como prioridade. Apenas $30 \%$ dos entrevistados comentaram que a matriz de treinamento contempla ferramentas da produção enxuta.

Nas centrais de ferramentas, $(50 \%)$ das empresas possibilitam entre 25 e 50 horas de treinamento por funcionário, e $20 \%$ possibilitam entre 50 e 75 horas/ano. De modo geral, nota-se que existe a preocupação com a capacitação dos funcionários das centrais de ferramentas.

Complementando as informações referentes à capacitação da mão de obra, questionou-se aos entrevistados se acreditavam que os funcionários da área produtiva sentiamse responsáveis pela utilização eficiente das ferramentas de corte. Sessenta porcento $(60 \%)$ dos entrevistados responderam que não, $30 \%$ consideram que sim, e $20 \%$ consideram que há uma conscientização crescente nesse sentido. Esses entrevistados colocam que treinamento, atribuição de responsabilidades e compartilhamento de metas seriam alternativas para gradualmente conseguir um maior comprometimento do pessoal da produção no tocante à utilização adequada de ferramentas de corte.

\subsection{Quantidade e tipos de componentes em estoque}

Os entrevistados declaram como política para determinar quantidade e tipo de componentes em estoque: avaliar o número de ferramentas que se possui em giro, os prazos de entrega e a estabilidade dos processos (riscos de ocorrerem danos).

\subsection{Definição e controle de vida de ferramentas}

A definição da vida útil de ferramentas é assunto de grande importância que deve ser realizado de maneira criteriosa. Cinquenta porcento $(50 \%)$ das empresas utilizam controle de vida de ferramentas através de fichas, onde são anotadas as vidas de ferramentas, com algumas diferenças entre os procedimentos. Algumas anotam a vida das ferramentas em uma ficha, outras utilizam uma ficha individual para cada ferramenta. Em uma das empresas, são anotadas na ficha apenas as anormalidades, o que difere da vida estabelecida. Vinte porcento (20\%) das empresas controlam não a vida, mas o consumo das ferramentas, comparando o que deveria ter sido gasto para determinado volume de produção e o que efetivamente se gastou. Essa forma de controle dificulta uma reação mais rápida quando anormalidades surgem. Em uma das empresas, existe um sistema que coleta as vidas de ferramenta diretamente do painel de controle das máquinas, fornecendo em um banco de dados vários parâmetros, como: vida programada e vida real, histórico de trocas contendo vida em que as ferramentas foram trocadas e quem as trocou, entre outras informações.

Um dos entrevistados coloca que o controle de vida de ferramenta, além dos registros em fichas, deve ser feito pelo pessoal da afiação e preset, através da análise crítica do desgaste das ferramentas que retornam da produção, determinando se a ferramenta encontra-se subtilizada ou sobreutilizada.

\subsection{Detecção de oscilação de vida de ferramenta}

A importância do controle adequado de vida de ferramenta está, além da quantificação precisa de custos, na detecção de oscilações de vida. A detecção é facilitada quando existe um padrão definido: se a ferramenta deve fazer 100 peças e fez 95, está fora do padrão.

Em 60\% das empresas a detecção do problema de variação de vida útil depende do aviso verbal da produção. Observa-se que os operadores são instruídos para isso, porém, não foi observado evidências de que existe padronização no fluxo e na estratégia de reação. O melhor exemplo de tratativa dessa questão foi observado em uma empresa onde existe um procedimento que determina que toda vez que uma ferramenta não cumprir a vida estabelecida, o operador deve preencher um cartão específico para anormalidades com ferramentas e anexá-lo à mesma. A ferramenta retorna para a central de ferramentas, em seu fluxo normal, e lá um técnico analisa e registra o problema em uma planilha de ocorrências. Em caso de recorrência de problema com determinada ferramenta, o técnico aciona o engenheiro de processo para tratar do assunto. Em outra empresa, que utiliza fichas para con- 
trolar a vida de ferramentas, são realizadas reuniões diárias de acompanhamento do desempenho das ferramentas. Em 20\% das empresas, os entrevistados colocaram que detectam variações de vida através de variação do consumo, o que torna o fluxo mais reativo.

Apesar da importância, a padronização de como detectar e reagir no caso de redução de vida de ferramentas é um tema pouco desenvolvido na maioria das empresas. Há oportunidade de melhorias nesse sentido, uma vez que a oscilação de vida de ferramentas é um distúrbio do processo que gera custos extras, paradas de máquina e possibilidade de refugos.

\subsection{Detecção e reação a problemas com ferramentas}

Além da oscilação de vida útil, abordada no tópico anterior, outros problemas como produto fora do especificado na troca, ou durante a vida da ferramenta, e quebras são frequentes nas linhas de produção. Foi perguntado aos entrevistados como eram detectados problemas em geral com ferramentas, como a informação chegava até os responsáveis e se havia fluxo definido. As respostas variaram desde "produção aciona técnico de ferramentas" a "não existe o fluxo". Apesar de em vários casos os entrevistados indicarem um fluxo de reação, em apenas uma empresa evidenciou-se fluxo definido e formalizado, constante em instrução de trabalho, em que o operador preenche um cartão sempre que uma anormalidade acontece (já descrito anteriormente para o caso de oscilação de vida útil). No tocante a problemas de qualidade devido a ferramentas, observa-se um fluxo um pouco mais formalizado, pois em geral, o departamento de qualidade é envolvido e é disparada a solução de problema envolvendo as centrais de ferramentas e engenharia de processo.

No que se refere à quebra de ferramentas, observou-se em $40 \%$ das empresas a forte preocupação de criar mecanismos para que, ao ocorrerem quebras, a produção não possa trocar ferramentas indiscriminadamente, quebrando várias ferramentas até que uma ação seja tomada ou até acabarem as ferramentas. Para tal, a solução adotada é limitar o número de ferramentas disponíveis ao lado da máquina (geralmente 2 ou 3), para que no caso de quebras além desse número seja necessário solicitar ferramentas à central, que então toma conhecimento do problema. Vinte porcento (20\%) dos entrevistados comentaram que foi criado um fluxo de reação bastante interessante para atuar no processo, contendo os passos básicos que devem ser checados em caso de quebras de ferramenta, como checar batimento da ferramenta, condições da refrigeração, fixação da peça e assim por diante. Esse tipo de iniciativa permite que a manutenção ou até mesmo os próprios operadores possam identificar problemas, poupando o tempo da central de ferramentas e o dos engenheiros de processo.
O registro das ocorrências de quebras aparenta ser a maior preocupação das centrais de ferramentas, pois $60 \%$ dos entrevistados indicaram a utilização de cartões ou fichas a serem preenchidos pela produção no caso de quebras de ferramentas.

Quando o problema de quebra é intermitente (quebras não subsequentes da mesma ferramenta), existe dificuldade maior de priorização dos problemas e ação eles. Em $60 \%$ das empresas, os entrevistados indicaram existir a compilação dos dados acumulados de ferramentas quebradas por períodos (gráficos de Pareto), gerando ações sobre os principais problemas.

Cem porcento (100\%) dos entrevistados indicaram haver sistemática para priorizar os principais problemas relativos a ferramentas a serem resolvidos, em comum acordo com a área produtiva e gerência, o que certamente pode ser facilitado e enriquecido por melhores sistemáticas para detectar os problemas e registrá-los.

\subsection{Aplicação do conceito Jidoka em ferramentas de corte}

Os exemplos citados pelos entrevistados foram quanto à utilização de poka-yokes, principalmente para impedir a montagem errada das ferramentas nas máquinas, para detectar quebras de ferramentas e para detectar anormalidades no processo, utilizando dispositivos que controlam o consumo de potência na máquina.

É importante que as centrais de ferramentas foquem em construir a qualidade nos processos, tornando as anormalidades visíveis em todas suas etapas e evitando recorrências.

\subsection{Gerenciamento visual}

Os exemplos mais comumente utilizados de gerenciamento visual relacionado a ferramentas de corte estão na utilização do Kanban e no uso de prateleiras e carrinhos porta-ferramenta com código de cores verde-vermelho, sendo verde ferramenta boa para uso e vermelho ferramenta usada ou que necessita de reparo.

Um entrevistado salienta a necessidade de todo estoque de ferramentas consumíveis estar visível, isto é, fora de gavetas $(30 \%$ dos entrevistados indicaram esta necessidade) e com códigos de cores que permitam identificar, somente através de uma rápida observação, se há alguma ferramenta com estoque abaixo do mínimo. Nessa empresa todo estoque de ferramentas está exposto em prateleiras, com etiquetas indicando os níveis verde, amarelo e vermelho do estoque, sendo que o amarelo indica necessidade de reposição e vermelho indica nível crítico. Também nessa empresa, as ferramentas são identificadas com códigos de cores que sinalizam a prioridade para preset 
em três níveis: ferramentas com baixa, média e alta vida útil. Ferramentas com menor vida útil ou menor quantidade em giro são identificadas com determinada cor, e são prioritárias. Foi citado também, como exemplo de gerenciamento visual, a utilização de kanban para controle das ferramentas a serem reafiadas.

\section{21 Metodologia de solução de problemas}

Os entrevistados tiveram alta concordância com as proposições: funcionários são envolvidos em programas de sugestões, são envolvidos no redesenho de processos e ferramentas com foco na melhoria contínua, e fazem parte de times de solução de problemas. Porém houve média concordância com a proposição funcionários são treinados em metodologias de resolução de problemas, indicando oportunidade de melhoria, pois uma vez que as demais respostas indicam alta motivação e alto incentivo para que os funcionários façam parte de grupos de solução de problemas e melhorias, ao somar-se a qualificação para tal, poderá obter-se ótimos resultados.

\subsection{Quantificação e controle do custo de ferramentas}

O gasto com ferramentas de corte foi apontado como o maior problema pelos entrevistados (Tabela 3). Entre eles: $50 \%$ indicaram quantificar o gasto com ferramentas em "custo por peça produzida"; $30 \%$ utilizam a base "gasto total no período"; $10 \%$ utilizam a base "custo para produzir 10.000 peças"; e $10 \%$ quantificam o gasto com ferramentas em termos de "percentual do faturamento líquido da fábrica". Quando se quantifica o gasto com ferramentas em "custo por peça produzida" obtém-se uma forma de visualizar os custos sem que seja necessário preocupar-se com as oscilações de volume, facilitando o controle, o que não ocorre quando utiliza-se a base gasto total no período.

Quanto aos componentes de custo que são considerados em relação a ferramentas de corte, $70 \%$ dos entrevistados contabilizam atualmente apenas o custo de aquisição de ferramentas, $20 \%$ contabilizam também custos de manutenção e recobertura e apenas $10 \%$ indicam contabilizar, além dos gastos de aquisição e recuperação, os gastos com mão de obra. Quarenta porcento (40\%) dos entrevistados salientarem a importância de se buscar quantificar o custo de forma mais completa.

Sessenta porcento (60\%) dos entrevistados souberam responder a pergunta sobre a que percentual do custo do produto final correspondia o custo com ferramentas de corte. Dentro desses, encontram os $50 \%$ com maior gasto anual com ferramentas, ou seja, existe a indicação de que o controle do gasto com ferramentas é maior onde gastase mais, como era de se esperar. O percentual do custo do produto relativo a ferramentas de corte oscilou entre $2 \%$ e $4 \%$, condizente com pesquisa realizada por Goldoni (2003), que indica média de $3 \%$.

Na produção enxuta, trata-se a redução de custos de forma ampla, buscando eliminar qualquer tipo de desperdício. Melhorias de lay-out que possam trazer redução nos tempos de preset, por exemplo, são abordadas como redução de custo. Dessa forma, uma quantificação mais ampla dos custos, envolvendo diversos fatores, pode facilitar a visualização de ganhos possíveis de serem obtidos através de princípios da produção enxuta. Outro ponto importante é que distúrbios no processo podem gerar custos por diversas formas, e não se percebe, nos relatos, a devida atenção a eles.

\section{23 Testes e substituição de ferramentas}

Todos os entrevistados, $100 \%$, indicaram que a realização de testes de ferramentas focam a redução de custo, o aumento da produtividade e a melhora na qualidade. Quarenta porcento $(40 \%)$ dos entrevistados indicaram também buscar a troca de fornecedores através dos testes realizados. Sessenta porcento $(60 \%)$ dos entrevistados indicaram que priorizam as operações em que serão realizados testes através do levantamento dos principais contribuidores do gasto para determinado produto, ou seja, buscam-se as ferramentas com maiores possibilidades de economia.

Procedimentos para realização de testes de ferramentas:

Para que testes e substituição de ferramentas realmente gerem ganhos para a empresa, sem a ocorrência de distúrbios, é necessário que haja uma sistemática para a sua realização. Foi perguntado aos entrevistados quanto à existência de procedimento, norma ou diretriz da empresa, indicando como proceder para a realização, aprovação de testes de ferramentas e implementação dos ítens aprovados. Sessenta $(60 \%)$ dos entrevistados indicaram a existência de procedimentos para tal. Desses, $50 \%$ indicaram oportunidades de melhoria nos procedimentos. Pelo indicado pela maioria dos entrevistados, atualmente os procedimentos cobrem partes do processo, tais como: como iniciar o teste, os cuidados com a documentação técnica ou os cuidados com a aprovação. Observa-se a oportunidade de, na maioria dos casos, tornar o procedimento mais sistêmico.

Critérios para aprovação de testes de ferramentas que visam a redução de custo:

Foi perguntado aos entrevistados que critérios compunham a quantificação dos ganhos visando a aprovação de testes de ferramentas para redução de custo: sessenta porcento $(60 \%)$ dos entrevistados indicaram como fundamental avaliar se mantêm-se os mesmos níveis de qualidade; custo por peça (custo da ferramenta dividido pelo total de peças que produz) apareceu como critério para 
$100 \%$ dos entrevistados; fator produtividade apareceu na composição para $50 \%$ dos entrevistados, caso trate-se de operação gargalo; $20 \%$ dos entrevistados indicaram a avaliação do custo de preparação da ferramenta e o custo de troca de ferramenta na máquina como componentes da avaliação de ganho; $10 \%$ indicaram que, caso haja necessidade de investimento para implementar a nova ferramenta (aquisição de corpos de fresa ou adaptadores por exemplo), o retorno deve ser menor que 12 meses; $10 \%$ indicaram que o prazo de entrega deve ser igual ou inferior ao do item a ser substituído.

O desenvolvimento de alternativas para redução de custo exige investimento por parte dos fornecedores. Como reconhecimento a isso, e para que o processo seja justo e mantenha-se o relacionamento ganha-ganha, $30 \%$ dos entrevistados mantêm políticas de tempo mínimo de fornecimento de um item após aprovado, ou seja, após aprovar determinado item, o fornecedor tem garantia de que esse será utilizado por um prazo mínimo antes de que seja aberta nova concorrência. Algumas empresas utilizam critérios distintos para ítens especiais e ítens de série, sendo que para ítens especiais esse compromisso chega a um ano de consumo. Com o mesmo objetivo — não prejudicar os fornecedores e manter um relacionamento forte - 80\% das empresas mantêm políticas de negociação quanto ao consumo de estoques remanescentes e em produção de ítens especiais, caso ocorra a sua substituição.

\section{Conclusões}

Neste artigo, foram apresentadas e discutidas as principais práticas relacionadas ao planejamento técnico do gerenciamento de ferramentas de corte na cidade de Curitiba e região metropolitana. Deve-se atentar para o fato de que os resultados e conclusões apresentados ao longo deste artigo devem ser consideradas com reserva, devido à limitação quanto à extensão da amostra pesquisada.

Na aplicação da pesquisa, observou-se grande receptividade e interesse dos entrevistados pelo tema em questão, reforçando a importância do gerenciamento de ferramentas no contexto atual. Foi obtido grande participação dos entrevistados, percebendo-se interesse em relatar problemas e iniciativas de sucesso. A amostra escolhida permitiu verificar as práticas de gerenciamento em empresas de médio e grande consumo de ferramentas de corte.

Há reconhecimento por parte dos entrevistados dos ganhos que podem ser obtidos aplicando o STP no gerenciamento de ferramentas de corte, havendo iniciativas nesse sentido. São utilizadas várias ferramentas da produção enxuta no gerenciamento de ferramentas, porém, nota-se também a necessidade de uma melhor estratégia de implementação. De modo geral, existe ambiente favorável para a utilização do STP no gerenciamento de ferramentas de corte na maioria das empresas entrevistadas.
Existe bom ambiente físico, comprometimento e confiança nas lideranças, bom ambiente de trabalho e boa comunicação nas centrais de ferramentas. Há oportunidades de melhoria no fluxo de informação entre departamentos, importante fator para o gerenciamento eficiente de ferramentas.

Os entrevistados apontaram a importância da existência de mão de obra capacitada nas centrais de ferramentas e indicaram a existência de profissionais qualificados em seus quadros de funcionários, havendo, porém, a necessidade de algum aprimoramento técnico. Observou-se oportunidades de melhoria no que se refere à programação de treinamentos na maioria das centrais, em especial com relação a produção enxuta. Declarou-se também haver dificuldade de encontrar profissionais treinados no mercado.

Os entrevistados possuem bom entendimento do que é o gerenciamento de ferramentas, do impacto que gera no sistema produtivo, e o enxergam como estratégia interdepartamental, embora não tenha sido possível evidenciar essa integração.

O principal problema relativo a ferramentas de corte apontado pelos entrevistados foi o custo. De fato, observou-se na abordagem de vários assuntos ao longo da pesquisa o foco direcionado a esse tema, havendo carência de priorização da estabilidade dos processos, fundamental para o gerenciamento eficiente de ferramentas de corte. Observou-se maior controle, como era esperado, em empresas com maior orçamento anual com ferramentas. Apesar de intenso foco na redução de custo, há oportunidades de melhoria em aspectos que são importantes para isso, como na implantação e expansão de base de dados de ferramentas e na quantificação mais ampla e precisa dos custos envolvidos com as mesmas. A redução do custo com ferramentas pode ir muito além da redução de preço e do aumento de vida útil das ferramentas, o que pode ser visualizado através da observação do processo de gerenciamento como um todo. A média de gasto com ferramentas de corte (aquisição) apontada pela maioria dos entrevistados equivale à média apontada no referencial teórico: $3 \%$ do custo do produto.

Ainda existe pouca atenção às ferramentas de corte durante o desenvolvimento de novos produtos, e há a participação efetiva dos fornecedores de ferramentas na seleção dessas para os processos.

Apenas metade da amostra indicou considerar a capabilidade dos processos durante a aprovação de novas ferramentas.

No que se refere à padronização, há entendimento dos benefícios, porém, foca-se na existência de instruções de 
trabalho para atividades básicas da área. Pouco evidenciou-se quanto à padronização de fluxos e outras atividades importantes para o gerenciamento: como o teste e a substituição de ferramentas e a detecção de anormalidades. De modo geral, existe falta de sistematização para detecção de distúrbios, no processo, ocasionados por problemas com ferramentas ou sua disponibilização. Poucos entrevistados indicaram a existência de uma estratégia e fluxo de reação definidos para quando problemas ocorrem.

Apesar da qualidade das ferramentas recebidas ter sido apontada como um grande problema enfrentado, somente em $40 \%$ das empresas (que estão entre as $50 \%$ com maior gasto com ferramentas) evidenciou-se uma efetiva sistemática de inspeção de recebimento de ferramentas. A prática da qualidade assegurada só foi apontada por $10 \%$ da amostra.

No tocante a testes de ferramentas, os entrevistados os realizam buscando principalmente reduções de custo e reduções de tempo de ciclo. A redução dos tempos de troca de ferramentas não foi apontada como prioridade.

Foram vistos bons exemplos de gerenciamento visual aplicado ao gerenciamento de ferramentas.

Há grande participação dos funcionários nos processos de melhoria e solução de problemas. Porém, há a necessidade dos mesmos serem melhores treinados para enxergar os desperdícios e para usarem ferramentas de solução de problemas, como já citado anteriormente.

\section{Agradecimentos}

Os autores gostariam de agradecer ao Programa de PósGraduação em Engenharia de Produção e Sistemas da Pontifícia Universidade Católica do Paraná (PPGEPSPUCPR) e à Empresa TRITEC Motors Ltda., pelo suporte financeiro para a realização desta pesquisa.

\section{Referências}

BOEHS, L. Gerenciamento de Ferramentas e Banco de Dados de Usinagem. Apostila, 1-201. Depto. de Eng. Mec. — Universidade Federal de Santa Catarina - Florianópolis, junho de 1994.
BOOGERT, R.M. Tool management in computer aided process planning. Utrecht: CIP — Data Koninklijke Bibliotheek, 1994.

FAVARETTO, A.S. Estudo do gerenciamento de ferramentas de corte na indústria automotiva de Curitiba e região Metropolitana. Curitiba, 2005. Dissertação (Mestrado em Engenharia de Produção) - Pontifícia Universidade Católica do Paraná.

MACCHIAROLI, R.; RIEMMA, S. Desing of a tool management system in a flexible cell. International journal o production research, UK, Taylor and Francis Ltda, v.34, n.3, 767-784, 1996.

MASINE, T. Improving productivity through tool tracking. University of Dundee, UK, 1998.

MATOSO, N. P.; CANCIGLIERI, O.; VALLE, P. D. Metodologia do gerenciamento do fluxo de ferramentas dentro da filosofia do Sistema Toyota de Fabricação. In: ENCONTRO NACIONAL DEENGENHARIA DE PRODUÇÃO, 23., 2003, Ouro Preto, Anais... Ouro Preto: ABEPRO, 2003.

NOGUEIRA, J.L.; RIBEIRO, M.V. Sistema de gerenciamento de ferramentas de corte assistido por computador. In: CONGRESSO BRASILEIRODEENGENHARIADE FABRICAÇÃO, 1, 2001, Curitiba. Anais. Paraná: Associação Brasileira de Ciências Mecânicas, 2001.

PERERA, T; MATTHEW, S. Analysis of tooling problems in discrete manufacturing industry. International journal of operation \& production management, Bradford, v.15, n.12, 76-86, 1995.

SPEAR, S.; BOWEN, H.K. Decoding the DNA of the Toyota Production System. Harvard Business Review, Harvard, sept-oct 1999.

TURINO, C.E. Redução de estoque de ferramentas de corte sem comprometimento da produtividade do chãode-fábrica. Florianópolis, 2002. 141f. Dissertação (Mestrado em Engenharia de Produção) — Universidade Federal de Santa Catarina. 